\title{
Responsive Glyco-poly(2-oxazoline)s: Synthesis, Cloud Point Tuning, and Lectin Binding
}

Kristian Kempe, ${ }^{\dagger}$ Christine Weber, ${ }^{+, \neq}$Krzysztof Babiuch, $^{+}$Michael Gottschaldt, ${ }^{+, \neq}$Richard Hoogenboom, ${ }^{\S}$ and Ulrich S. Schubert ${ }^{*,+,}$

\author{
${ }^{\dagger}$ Laboratory of Organic and Macromolecular Chemistry (IOMC) and Jena Center for Soft Matter (JCSM), \\ Friedrich-Schiller-University Jena, Humboldtstr. 10, 07743 Jena, Germany \\ ${ }^{\ddagger}$ Dutch Polymer Institute (DPI), John F. Kennedylaan 2, 5612 AB Eindhoven, The Netherlands \\ ${ }^{\S}$ Supramolecular Chemistry Group, Department of Organic Chemistry, Ghent University, Krijgslaan 281 S4, B-9000 Ghent, Belgium \\ Supporting Information
}

ABSTRACT: A new sugar-substituted 2-oxazoline monomer was prepared using the copper-catalyzed alkyne-azide cycloaddition (CuAAC) reaction. Its copolymerization with 2-ethyl-2-oxazoline as well as 2-(dec-9-enyl)-2-oxazoline, yielding well-defined copolymers with the possibility to tune the properties by thiol-ene "click" reactions, is described. Extensive solubility studies on the corresponding glycocopolymers demonstrated that the lower critical solution temperature behavior and $\mathrm{pH}$-responsiveness of these copolymers can be adjusted in water and phosphatebuffered saline (PBS) depending on the choice of the thiol. By conjugation of $2,3,4,6$-tetra- $O$-acetyl-1-thio- $\beta$-D-glucopyranose and subsequent deprotection of the sugar moieties, the hydrophilicity of the copolymer could be increased significantly, allowing a cloud-point tuning in the physiological range. Furthermore, the binding capability of the glycosylated copoly(2-oxazoline) to concanavalin A was investigated.

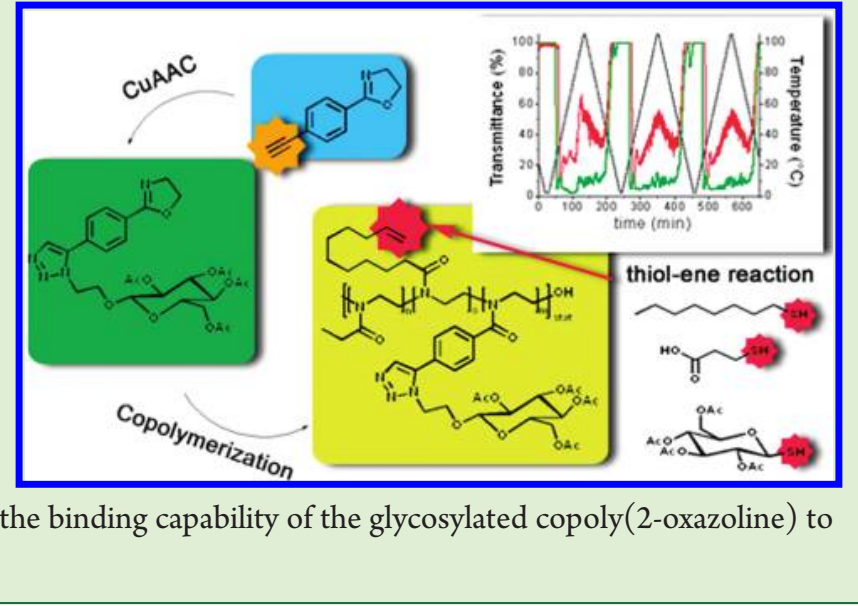

\section{INTRODUCTION}

The ability of neoglycopolymers to mimic the behavior of naturally existing glycoconjugates is one of the various reasons that cause the ever-increasing interest in new synthetic carbohydrate-substituted polymers. These polymers can be seen as materials at the interface of polymer science and biology encompassing both the bioactive properties of carbohydrates and the material properties of well-known synthetic polymer backbones. As a result, potentially biocompatible materials that offer a good water solubility combined with a bioactivity similar to natural conjugates are formed. Carbohydrates are involved in a large number of biological processes, thus, playing an important role in, for instance, cell development, immune response, and cancer metastasis. ${ }^{1}$ The recognition of such carbohydrates is associated mainly with defined carbohydrate-protein interactions to carbohydrate-binding proteins (lectins), which are responsible, for example, for cell proliferation and death., ${ }^{2,3}$ The generally weak interaction between proteins and individual mono- and disaccharides is circumvented by multivalent interactions employed by biological systems, which is known as the "cluster glycoside effect". ${ }^{-6}$ For this purpose, synthetic polymers that can act as multivalent ligands, exhibiting various carbohydrate moieties along the polymer backbone, are highly desired. They can be designed by the incorporation of pendant or terminal carbohydrate groups, which, in turn, are attached using two different approaches: either by the synthesis of carbohydratecontaining monomers and their subsequent polymerization ${ }^{7,8}$ or by the postmodification of preformed polymers. ${ }^{9}$ Besides common ways to couple hydroxyl-functionalized groups to a monomer/polymer containing, for example, carboxy groups "click reactions" provide access to a wide range of glycopolymers. ${ }^{10}$

To date, only a few investigations have focused on the syntheses of glycopolymers via ring-opening polymerizations. ${ }^{11-13}$ Nevertheless, the cationic ring-opening polymerization (CROP) of 2-oxazoline represents a further versatile technique for the synthesis of well-defined (co)polymers, which was first reported in 1966 by four independent groups. ${ }^{14-17}$ Poly(2-oxazoline)s themselves can be considered as analogues of poly(amino acid)s, that is, pseudopeptides, exhibiting a stealth behavior similar to poly(ethylene oxide) (PEO). ${ }^{18}$ Because of their biocompatibility, (co)poly(2-oxazoline)s were employed in several biomedical applications. ${ }^{19,20}$ These properties, in combination with the LCST behavior of, for example, 2-ethyl-2-oxazoline (EtOx) in water, ${ }^{21}$ make them perfectly suited polymeric backbones for the

Received: March 21, 2011

Revised: $\quad$ May 17, 2011

Published: May 17, 2011 
Scheme 1. Schematic Representation of the Mechanism of the Cationic Ring-Opening Polymerization of 2-Oxazolines
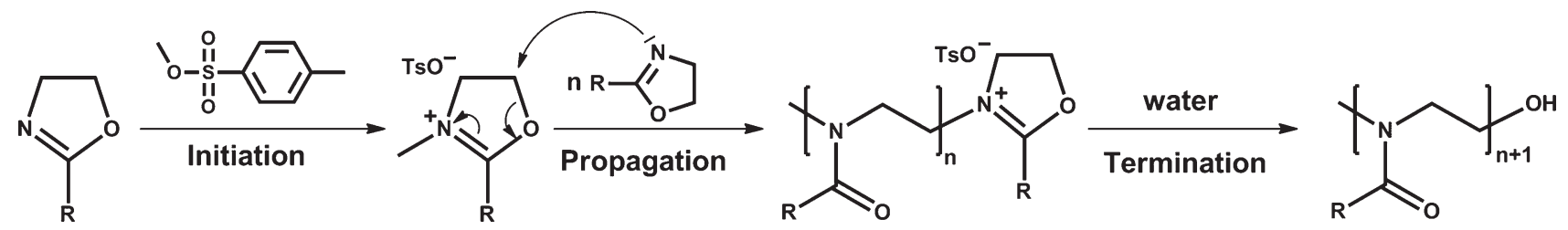

synthesis of glyco-(co)polymers with various tunable properties. Furthermore, under appropriate conditions, this technique yields polymers with narrow molar mass distributions, as indicated by low polydispersity index (PDI) values. The absence or at least minimization of chain transfer and termination reactions are the prerequisite for the living manner of the CROP. This, in turn, allows the incorporation of a second monomer into the polymer chain after the full consumption of the first monomer by sequential monomer addition. Therefore, the incorporation of different functionalities can be achieved either by the functional initiator or termination method or by the polymerization of 2-substituted-2-oxazolines. ${ }^{22-24}$ Any electrophile, in the simplest case an acid or even a Lewis acid, can initiate the polymerization by the formation of an oxazolinium species. Possessing a weakened CO-bond, the "activated" monomer is prone to undergo a nucleophilic attack by the nitrogen atom of another monomer. ${ }^{25-28}$ The resulting propagating species is growing either as long as the monomer is available or until the addition of a nucleophile to the reaction mixture, which terminates the polymerization. A schematic representation of the polymerization mechanism is depicted in Scheme 1.

To the best of our knowledge, there is only one report published that discusses the synthesis as well as the polymerization of a sugar-functionalized 2-oxazoline. ${ }^{29}$ This might be due to an expected incompatibility with the conditions of the cationic polymerization, which can be inhibited by the free electron pairs of oxygen-, nitrogen-, or even sulfur-containing monomers. However, Cortez and Grayson, for instance, prepared different 2-oxazoline monomers with thiol-ether bonds, which could be polymerized under CROP conditions, even if the accessible molar masses were rather low. ${ }^{30}$ Furthermore, Nuyken et al. demonstrated the synthesis of carboxy as well as amino-containing copoly(2-oxazoline)s. ${ }^{31,32}$ Moreover, Aoi et al. were even able to polymerize 2-methyl-2-oxazoline and 2-phenyl-2-oxazoline using $N$-acetyl-D-glucosamine derivatives as initiators. ${ }^{33}$ The above-mentioned results encouraged us to target the synthesis of a new sugar-substituted 2-oxazoline and its copolymerization with EtOx and 2-(dec-9-enyl)-2-oxazoline (DecEnOx) containing double bonds for a further modification of the obtained glycopolymers by thiol-ene photoaddition reactions. The sugar-substituted 2-oxazoline monomer is obtained in a copper-catalyzed alkyneazide cycloaddition ( $\mathrm{CuAAc}$ ) approach, which provides a straightforward synthetic route for the preparation of various sugarsubstituted 2-oxazolines. The usage of "click" reactions, in particular, for the monomer synthesis, allows for a simple variation of the sugar moiety by just one reaction step to obtain further monomers instead of repeating the complete monomer synthesis from the respective sugar again. Furthermore, the thiolene addition of sugars to terminal alkenes is known to be very efficient and thus provides one of the known methods for sugar conjugation to polymers. By reacting the copolymers with thiols of different hydrophilicity, their thermo- as well as $\mathrm{pH}$-responsive properties could be tuned as determined by extensive cloud-point studies. Furthermore, the bioavailability of the carbohydrate moieties on the polymeric backbone was investigated by the interaction of the copolymers with a lectin (ConA).

\section{EXPERIMENTAL PART}

Materials. 4-Bromobenzonitrile, 2-aminoethanol, acetonitrile, sodium methanolate, and 2,2-dimethoxy-2-phenylacetophenone (DMPA) were purchased from Sigma-Aldrich and were used as received. 2-Ethyl-2oxazoline and methyl tosylate were obtained from Acros Chemicals and were distilled to dryness over barium oxide $(\mathrm{BaO})$ and stored under argon. 2,3,4,6-Tetra- $O$-acetyl-1-thio- $\beta$-D-glucopyranose (>99\%, GlcAcSH) was purchased from GLYCON Biochem. GmbH. (2-Azidoethyl)-1- $\beta$-Dglucopyranose tetraacetate was synthesized as reported. ${ }^{34}$ Thiols (dodecanethiol, 3-mercaptopropionic acid) were purchased from Acros Chemicals and Concanavalin A from AppliChem. For the cloud-point measurements, phosphate-buffered saline (PBS) $10 \times$ concentrate (Aldrich), citrate-buffered solution ( $\mathrm{pH} \mathrm{4,} \mathrm{Roth),} \mathrm{and} \mathrm{borate-buffered}$ solution ( $\mathrm{pH} \mathrm{10,} \mathrm{Roth)} \mathrm{were} \mathrm{used.}$

General Methods and Instrumentation. Polymerizations were performed under microwave irradiation with temperature control in an Emrys Liberator single-mode microwave synthesizer from Biotage equipped with a noninvasive IR sensor (accuracy: $\pm 2 \%$ ). Microwave vials were heated to $110{ }^{\circ} \mathrm{C}$ overnight and allowed to cool to room temperature under argon before usage. Gas chromatography (GC) was measured on an Interscience Trace gas chromatograph with a trace column RTX-5 connected to a PAL autosampler. Size exclusion chromatography (SEC) measurements were performed on an Agilent system. Two PSS SDV ( $5 \mu \mathrm{m}$ pore size) columns were placed in series. DMA with $5 \mathrm{mmol}$ of $\mathrm{LiCl}$ was used as eluent at $1 \mathrm{~mL} / \mathrm{min}$ flow rate, and the column oven temperature was set to $50{ }^{\circ} \mathrm{C}$. The molar mass was calculated according to polystyrene standards (from PSS). For preparative SEC, Bio-Beads S-X1 (cross-linked polystyrene beads) from BioRad were used. ${ }^{1} \mathrm{H}$ NMR spectra of the products were recorded on a Bruker Avance $300 \mathrm{MHz}$ spectrometer at room temperature, with $\mathrm{CDCl}_{3}$ or $\mathrm{MeOH}-d_{4}$ as solvent. The chemical shifts are given in ppm relative to the residual nondeuterated solvent signals. Dynamic light scattering (DLS) measurements were carried out on a Zetasizer Nano ZS (Malvern Instrument, Malvern, U.K.) using a He/Ne laser $(\lambda=$ $633 \mathrm{~nm})$ and a scattering angle of $173^{\circ}$. The mean particles size was approximated as the effective ( $\mathrm{Z}$ average) diameter and the width of the distribution as the polydispersity index of the particles $\left(\mathrm{PDI}_{\text {particle }}\right)$ obtained by the cumulants method assuming a spherical shape. Cloud points were determined in a Crystal 16 from Avantium Technologies connected to a chiller (Julabo FP 40) at a wavelength of $500 \mathrm{~nm}$. The solutions were heated and cooled at a rate of $1{ }^{\circ} \mathrm{C} \mathrm{min}-1$. The cloudpoint temperature is reported as the temperature where the transmittance decreased to $50 \%$ in the second heating run.

Monomer Synthesis. 2-(4-Bromophenyl)-2-oxazoline (2). 4-Bromobenzonitrile (1), $5.01 \mathrm{~g},(27.52 \mathrm{mmol})$ and zincacetate-dihydrate, $210 \mathrm{mg}$, 
(0.96 mmol) in $15 \mathrm{~mL}$ of chlorobenzene were heated to $130{ }^{\circ} \mathrm{C}$ under an argon atmosphere. Subsequently, $2.20 \mathrm{~mL}$ of 2-aminoethanol $(2.22 \mathrm{~g}$, $36.38 \mathrm{mmol}$ ) was added via syringe within $5 \mathrm{~min}$, and stirring at $130^{\circ} \mathrm{C}$ was continued for additional $16 \mathrm{~h}$. The mixture was allowed to reach ambient temperature and diluted with $100 \mathrm{~mL}$ of dichloromethane. The organic phase was washed four times with water, twice with brine, and dried over $\mathrm{MgSO}_{4}$. After removal of the solvent under reduced pressure, $5.25 \mathrm{~g}(23.22 \mathrm{mmol})$ of a colorless solid of high purity were obtained. Recrystallization from cyclohexane gave $4.32 \mathrm{~g}$ ( $19.13 \mathrm{mmol})$ of 2 as colorless solid in $70 \%$ yield. ${ }^{1} \mathrm{H}$ NMR (300 $\left.\mathrm{MHz}, \mathrm{CDCl}_{3}, \delta\right): 7.80\left(2 \mathrm{H}, \mathrm{d},{ }^{3} J(\mathrm{H} 2, \mathrm{H} 3)={ }^{3} J(\mathrm{H} 5, \mathrm{H} 6)=8.4 \mathrm{~Hz}, \mathrm{H} 2 / \mathrm{H} 6\right.$ phenyl), $7.54\left(2 \mathrm{H}, \mathrm{d},{ }^{3} \mathrm{~J}(\mathrm{H} 2, \mathrm{H} 3)={ }^{3} \mathrm{~J}(\mathrm{H} 5, \mathrm{H} 6)=8.4 \mathrm{~Hz}, \mathrm{H} 3 / \mathrm{H} 5\right.$ phenyl), $4.04\left(2 \mathrm{H}, \mathrm{t},{ }^{3} \mathrm{~J}\left(\mathrm{CH}_{2} \mathrm{O}\right.\right.$ ox, $\mathrm{CH}_{2} \mathrm{~N}$ ox $)=9.5 \mathrm{~Hz}, \mathrm{CH}_{2} \mathrm{O}$ ox $), 4.43(2 \mathrm{H}, \mathrm{t}$, ${ }^{3} J\left(\mathrm{CH}_{2} \mathrm{~N}\right.$ ox, $\mathrm{CH}_{2} \mathrm{O}$ ox $)=9.5 \mathrm{~Hz}, \mathrm{CH}_{2} \mathrm{~N}$ ox $) .{ }^{13} \mathrm{C} \mathrm{NMR}\left(300 \mathrm{MHz}, \mathrm{CDCl}_{3}\right.$, $\delta): 163.83$ (C ox ), 131.58, 129.65, 126.65, 125.90 (C phenyl), $67.76\left(\mathrm{CH}_{2} \mathrm{O}\right.$ ox), $54.97\left(\mathrm{CH}_{2} \mathrm{~N}\right.$ ox $)$. Anal. calcd for $\mathrm{C}_{9} \mathrm{H}_{8} \mathrm{NOBr}$ : C, 47.82; H, 3.57; Br, 35.34; N, 6.20; found: C, 47.94; $\mathrm{H}, 3.58 ; \mathrm{N}, 6.19$.

2-(4-Trimethylsilylethynylphenyl)-2-oxazoline (3). 2 (2.5 g, $11 \mathrm{mmol}$ ) was dissolved in $100 \mathrm{~mL}$ of dry $N, N^{\prime}$-diisopropylamine, and CuI $(26.8 \mathrm{mg}$, $0.14 \mathrm{mmol})$ as well as $\mathrm{Pd}\left(\mathrm{PPh}_{3}\right)_{2} \mathrm{Cl}_{2},(147.8 \mathrm{mg}, 0.21 \mathrm{mmol})$ were added under an argon atmosphere. We added $2.1 \mathrm{~mL}(1.46 \mathrm{~g}, 14.9 \mathrm{mmol})$ of trimethylsilylacetylene dropwise within $15 \mathrm{~min}$, and the mixture was heated to $70{ }^{\circ} \mathrm{C}$ for $3 \mathrm{~h}$. Subsequently, the mixture was allowed to reach ambient temperature and was filtered over neutral aluminum oxide. The dry sludge was washed with $n$-hexane, and the combined organic phases were evaporated to dryness. We obtained $2.54 \mathrm{~g}(10.4 \mathrm{mmol}, 94 \%)$ of 3 as a black-colored oil that crystallized at room temperature. The crude product was used without further purification.

2-(4-Ethynylphenyl)-2-oxazoline (4). We dissolved $2.54 \mathrm{~g}$ (10.4 mmol) of 3 in $60 \mathrm{~mL}$ of THF and $60 \mathrm{~mL} \mathrm{MeOH}$. KF (1.78 g, $30.6 \mathrm{mmol})$ was added, and stirring was continued for an additional hour at room temperature. The reaction mixture was filtered through neutral aluminum oxide, and the dry sludge was washed with $n$-hexane, and the combined organic phases were evaporated to dryness. We obtained $1.56 \mathrm{~g}(9 \mathrm{mmol}$, $87 \%)$ of 4 as a brown solid. Further purification was managed by sublimation $\left(70{ }^{\circ} \mathrm{C} / 1 \times 10^{-2}\right.$ Torr $)$ to give $1.32 \mathrm{~g}(7.7 \mathrm{mmol})$ of 4 as yellow, crystalline powder in $74 \%$ yield. ${ }^{1} \mathrm{H} \mathrm{NMR}\left(300 \mathrm{MHz}, \mathrm{CDCl}_{3}, \delta\right)$ : $7.89\left(2 \mathrm{H}, \mathrm{d},{ }^{3} \mathrm{~J}(\mathrm{H} 2, \mathrm{H} 3)={ }^{3} J(\mathrm{H} 5, \mathrm{H} 6)=8.4 \mathrm{~Hz}, \mathrm{H} 3 / \mathrm{H} 5\right.$ phenyl $), 7.52$ $\left(2 \mathrm{H}, \mathrm{d},{ }^{3} J(\mathrm{H} 2, \mathrm{H} 3)={ }^{3} J(\mathrm{H} 5, \mathrm{H} 6)=8.4 \mathrm{~Hz}, \mathrm{H} 2 / \mathrm{H} 6\right.$ phenyl $), 4.45(2 \mathrm{H}, \mathrm{t}$, ${ }^{3} J\left(\mathrm{CH}_{2} \mathrm{O}\right.$ ox, $\mathrm{CH}_{2} \mathrm{~N}$ ox $)=9.6 \mathrm{~Hz}, \mathrm{CH}_{2} \mathrm{O}$ ox $), 4.08\left(2 \mathrm{H}, \mathrm{t},{ }^{3} J\left(\mathrm{CH}_{2} \mathrm{~N}\right.\right.$ ox, $\mathrm{CH}_{2} \mathrm{O}$ ox $)=9.6 \mathrm{~Hz}, \mathrm{CH}_{2} \mathrm{~N}$ ox $), 3.19(1 \mathrm{H}, \mathrm{s}, \mathrm{CH}) .{ }^{13} \mathrm{C} \mathrm{NMR}(300 \mathrm{MHz}$, $\mathrm{CDCl}_{3}, \delta$ ): 163.99 (C ox), 132.99, 128.02, 127.91, 124.98 (C phenyl), 83.04 (C acetylene), 79.24 ( $\mathrm{CH}$ acetylene), $67.70\left(\mathrm{CH}_{2} \mathrm{O}\right.$ ox), 55.00 $\left(\mathrm{CH}_{2} \mathrm{~N}\right.$ ox $)$. Anal. calcd for $\mathrm{C}_{11} \mathrm{H}_{9} \mathrm{NO}$ : C, $77.17 ; \mathrm{H}, 5.30 ; \mathrm{N}, 8.18$; found: C, 77.07; H, 5.41; N, 8.15.

$A C_{4} G / c Y n O x$ (5). In a $100 \mathrm{~mL}$ round-bottomed flask, (2-azidoethyl)1 - $\beta$-D-glucopyranose tetraacetate $(3.0 \mathrm{~g}, 7.19 \mathrm{mmol}), 4(1.231 \mathrm{~g}, 7.19$ $\mathrm{mmol})$, sodium ascorbate $(0.143 \mathrm{~g}, 0.72 \mathrm{mmol})$, and copper(II) acetate $(0.108 \mathrm{~g}, 0.72 \mathrm{mmol})$ were mixed in $80 \mathrm{~mL}$ of THF/ $\mathrm{H}_{2} \mathrm{O}(5: 1)$. The reaction mixture was stirred under an argon atmosphere until complete disappearance of the starting materials ( $4 \mathrm{~h}$, TLC monitoring, EtOAc/ Hex 2:1). After dilution with EtOAc and washing with water (three times), the solution was dried over magnesium sulfate, filtered, and dried under vacuum to yield $4.2 \mathrm{~g}$ of a yellowish, solid foam. The product was purified by column chromatography $\left(\mathrm{SiO}_{2}, \mathrm{EtOAc} / \mathrm{Hex} 4: 1\right)$ and triple recrystallization from ethanol to afford $2.5 \mathrm{~g}$ of a white, crystalline powder $(60 \%) .{ }^{1} \mathrm{H}$ NMR $\left(300 \mathrm{MHz}, \mathrm{CDCl}_{3}, \delta\right): 8.05-7.85(5 \mathrm{H}, \mathrm{m}, 4 \mathrm{H}$ phenyl, $1 \mathrm{H}$ triazole); $5.22-4.96$ (3H, m, Glc: $\mathrm{H} 2, \mathrm{H} 3, \mathrm{H} 4)$; 4.76-4.62 $\left(1 \mathrm{H}, \mathrm{m}, \mathrm{CH}_{2}-\mathrm{N}\right.$ linker); 4.60-4.51 ( $1 \mathrm{H}, \mathrm{m}, \mathrm{CH}_{2}-\mathrm{N}$ linker); $4.50-4.37$ (3H, m, $\mathrm{CH}_{2}-\mathrm{O}$ ox, Glc: $\left.\mathrm{H1}\right) ; 4.33-4.19\left(2 \mathrm{H}, \mathrm{m}, \mathrm{CH}_{2}-\mathrm{O}\right.$ linker, Glc: H6); 4.18-4.00 (3H, m, $\mathrm{CH}_{2}-\mathrm{N}$ ox, Glc: $\left.\mathrm{H6}^{\prime}\right)$; $3.97-3.83$ ( $1 \mathrm{H}, \mathrm{m}, \mathrm{CH}_{2}-\mathrm{O}$ linker); 3.76-3.62 (1H, m, Glc: $\left.\mathrm{H} 5\right) ; 2.06$ (1H, s, OAc); 2.01 (3H, s, OAc); 2.00 (3H, s, OAc); 1.7 (3H, s, OAc). ${ }^{13} \mathrm{C}$ NMR $\left(300 \mathrm{MHz}, \mathrm{CDCl}_{3}, \delta\right): 170.5,170.0,2 \times 169.4$ (COOAc); 164.3 (C ox); 146.8 (C triazole); 133.3, 128.7, 127.3, 125.4 (phenyl); 122.0
(CH triazole); 100.5 (Glc: C1); 72.3 (Glc: C5); 72.0 (Glc: C4); 70.9 (Glc: C2); 68.2 (Glc: C3); 67.7 (Glc: C6); $67.6\left(\mathrm{CH}_{2}-\mathrm{O}\right.$ linker); 61.7 $\left(\mathrm{CH}_{2}-\mathrm{O}\right.$ ox $) ; 55.0\left(\mathrm{CH}_{2}-\mathrm{O}\right.$ linker $) ; 50.1\left(\mathrm{CH}_{2}-\mathrm{N}\right.$ ox $) ; 20.7-20.3$ (4× $\mathrm{CH}_{3} \mathrm{OAc}$ ). Anal. calcd for $\mathrm{C}_{27} \mathrm{H}_{32} \mathrm{~N}_{4} \mathrm{O}_{11}: \mathrm{C}, 55.10 ; \mathrm{H}, 5.48 ; \mathrm{N}$, 9.52; found: C, 55.12; $\mathrm{H}, 5.53 ; \mathrm{N}, 9.31$.

DecEnOx. The 2-(dec-9-enyl)-2-oxazoline (DecEnOx) was synthesized according to the literature. ${ }^{35}$

Microwave-Assisted Copolymerization of EtOx and $\mathrm{Ac}_{4} \mathrm{Gl}-$ cYnOx: General Procedure. For the kinetic studies, a stock solution containing initiator (methyl tosylate), monomers (EtOx and $\mathrm{Ac}_{4} \mathrm{Glc}$ YnOx), and solvent (acetonitrile) was prepared. The total monomer concentration was adjusted to $1.5 \mathrm{M}$ and a total monomer to initiator $([\mathrm{M}] /[\mathrm{I}])$ ratio of 20 was applied containing $10 \mathrm{~mol} \% \mathrm{Ac}_{4} \mathrm{GlcYnOx}$. The stock solution was divided over seven polymerization vials that were capped under argon. For the calculation of the conversion, three $t_{0}$ samples were taken. The vials were heated to $100{ }^{\circ} \mathrm{C}$ for different times in the microwave synthesizer. After cooling, the reaction was quenched by the addition of $50 \mu \mathrm{L}$ of water. GC and SEC samples were prepared to determine the monomer conversion and the molar masses of the polymer, respectively. For the calculations of the monomer conversions, the polymerization solvent was used as internal standard.

Preparation of the Copolymer P1. A polymerization solution containing initiator, monomers (EtOx, $\mathrm{Ac}_{4} \mathrm{GlcYnOx}, \mathrm{DecEnOx}$ ), and solvent (acetonitrile) was irradiated in the microwave at $120^{\circ} \mathrm{C}$ for $12 \mathrm{~h}$ to reach full conversion of all three monomers. The full consumption of the monomers was assured by ${ }^{1} \mathrm{H}$ NMR spectroscopy and SEC investigations. The resulting polymer was dissolved in chloroform and washed twice with water and brine before precipitation into ice-cold diethyl ether.

Thiol-ene Photoaddition Reactions of P1 Using Different Thiols. For each reaction, $150 \mathrm{mg}$ of copolymer P1 was dissolved in $\mathrm{THF}$, and the thiol component was added in excess with respect to the double bonds (2-fold excess (GlcAcSH) and a 10-fold excess (dodecane thiol, 3-mercaptopropionic acid), respectively). After degassing the solution for $30 \mathrm{~min}, 2$,2-dimethoxy-2-phenylacetophenone (DMPA) was added, and the solution was irradiated at $356 \mathrm{~nm}$ using a $6 \mathrm{~W}$ handheld UV lamp overnight. The resulting copolymers $(\mathbf{P 2 a}-\mathbf{c})$ were purified by precipitation in ice-cold diethyl ether.

Deprotection of the Copolymers P1, P2a-c. We dissolved $20 \mathrm{mg}$ of each copolymer in $1 \mathrm{~mL}$ of dry dichloromethane. Subsequently, $0.1 \mathrm{~mL}$ of $2.0 \mathrm{M}$ sodium methanolate solution in methanol was added, and the copolymer solution was stirred for $2 \mathrm{~h}$. After neutralization with Dowex 50WX8-200 $\mathrm{H}^{+}$-loaded resin, the solution was concentrated under reduced pressure, and the glycopolymers $(\mathbf{P} 3, \mathbf{P} 4 \mathbf{a}-\mathbf{c})$ were precipitated in ice-cold diethyl ether.

Cloud-Point Measurements. The copolymers P3 and P4a-c were dissolved at a constant concentration of $4 \mathrm{mg} \mathrm{mL}^{-1}$ in deionized water, 0.015 and $0.005 \mathrm{mM} \mathrm{NaCl}$ aqueous solutions, as well as PBS. Additionally, P4b was dissolved in $\mathrm{pH} 4$ and 10 buffer solution. The turbidity of the solutions was determined in two temperature cycles ranging from 2 to $105{ }^{\circ} \mathrm{C}$. The concentration dependence of the cloud point was investigated using P4c in PBS buffer (0.5, 1.0, 2.0, $\left.4.0 \mathrm{mg} \cdot \mathrm{mL}^{-1}\right)$.

Lectin Binding Studies. Stock solutions of ConA in PBS $\left(4 \mathrm{mg} \cdot \mathrm{mL}^{-1}\right)$ and $\mathbf{P} 4 \mathrm{c}$ in PBS $\left(4 \mathrm{mg} \cdot \mathrm{mL}^{-1}\right)$ were prepared. To study the aggregation of ConA with P4c, we diluted the stock solutions with PBS to gain different concentrations of one component while keeping the other one constant. The turbidity of the solution was measured using the Crystal16. A solution of ConA and P4c with a total volume of $750 \mu \mathrm{L}$ was placed in the Crystal16 and stirred for $10 \mathrm{~min}$ at $25^{\circ} \mathrm{C}$. After the addition of the second component (either P4c or ConA), the transmittance of the solution was automatically measured over a time range of $15 \mathrm{~min}$. For conjugation studies, $1 \mathrm{~mL}$ of a $1 \mathrm{mg} \cdot \mathrm{mL}^{-1}$ solution of $\mathbf{P 4 c}$ was stirred $10 \mathrm{~min}$ prior to the addition of lectin at $37^{\circ} \mathrm{C}$. We directly 
Scheme 2. Schematic Representation of the Synthesis of $\mathrm{Ac}_{4}$ GlcYnOx and Graphical Illustration of the Other Monomers (EtOx; DecEnOx) Used for the Copolymerization (bottom, left)

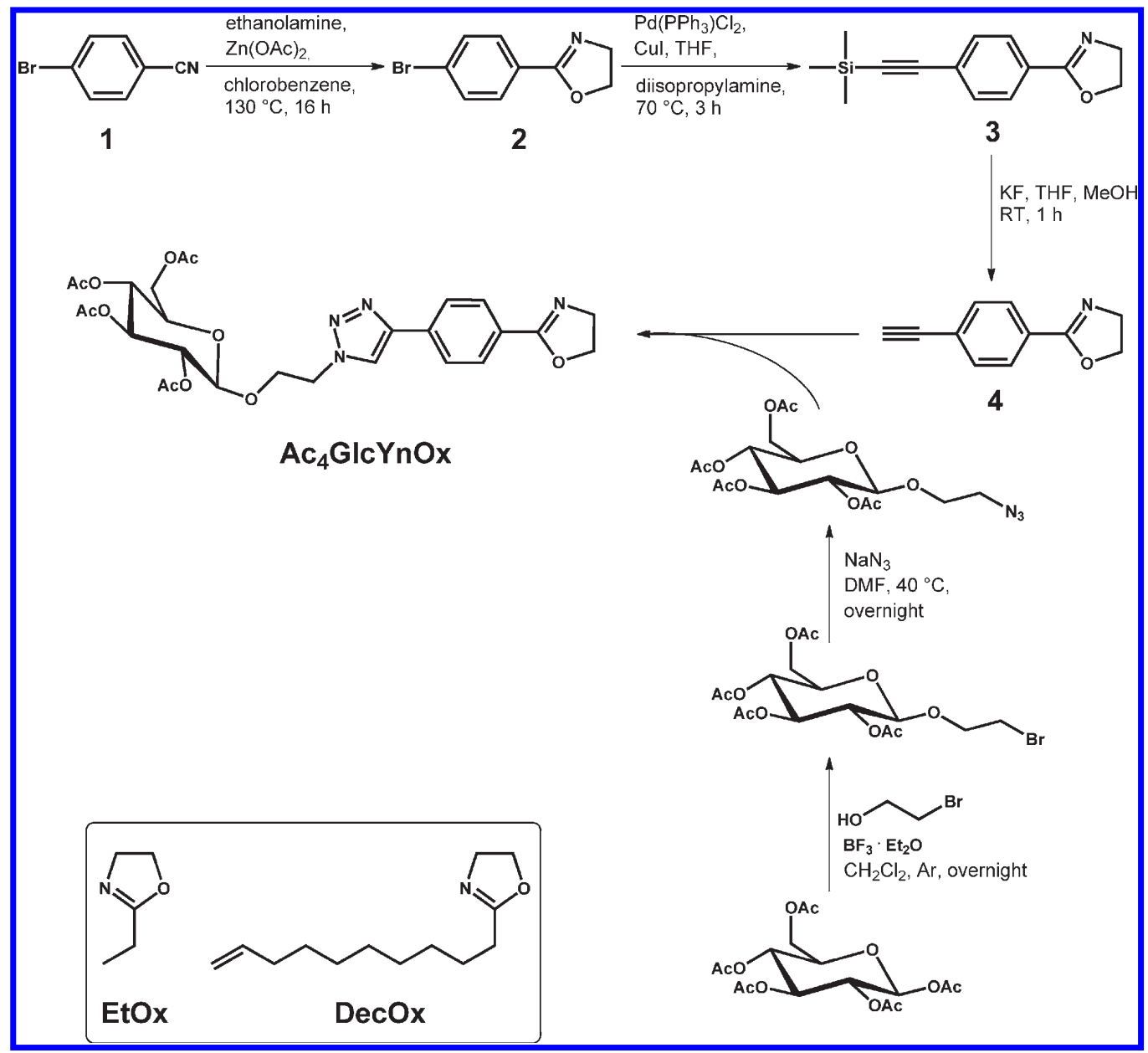

added $2 \mathrm{mg}$ of ConA to the solution, and the time before the mixture became turbid was measured.

\section{RESULTS AND DISCUSSION}

Monomer Synthesis. The preparation procedure of $\mathrm{Ac}_{4} \mathrm{Glc}$ YnOx encompasses a three-step synthesis based on the formation of a 2-oxazoline ring in the first stage (Scheme 2), which represents a well-known route for 2-oxazolines adapted from Witte and Seeliger. ${ }^{36}$ Starting from 4-bromobenzonitrile, the corresponding 2-oxazoline (2) can be prepared by the reaction with 2 -aminoethanol in the presence of a Lewis-acid catalyst. 2 was subsequently modified with a trimethylsilyl-protected alkyne to prevent a reaction with the second acetylene proton. The product of the Sonogashira coupling (3) was used without further purification. After dissolving 3 in a 1:1 mixture of $\mathrm{THF} / \mathrm{MeOH}$, potassium fluoride was added to cleave the protecting group to yield compound 4 bearing an active triple bond suitable for CuAAC reactions. These reactions between alkynes and azides are known to be highly efficient. They generally show a fast conversion to the desired product with only minor side products. The (2-azidoethyl)-1- $\beta$-D-glucopyranose tetraacetate was synthesized as previously reported. ${ }^{34}$ The glucose-substituted 2-oxazoline monomer was obtained in a

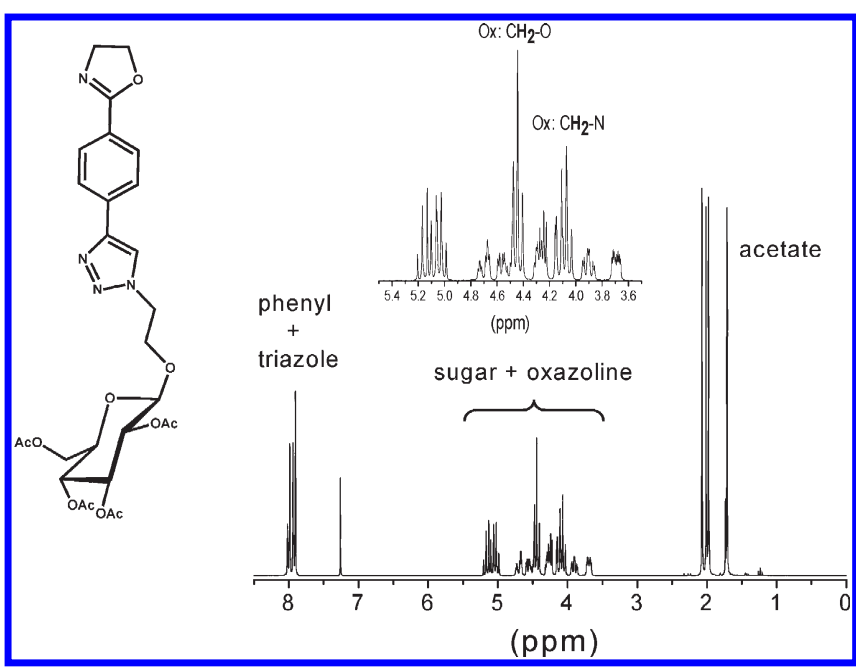

Figure 1. Details of the ${ }^{1} \mathrm{H}$ NMR spectrum of $\mathrm{Ac}_{4} \mathrm{GlcYnOx}\left(\mathrm{CDCl}_{3}\right.$, $300 \mathrm{MHz}$ ).

CuAAC approach using $\mathrm{Cu}$ (II) acetate and sodium ascorbate. For removal of the copper catalyst, the product was intensively washed, purified by column chromatography, and recrystallized 


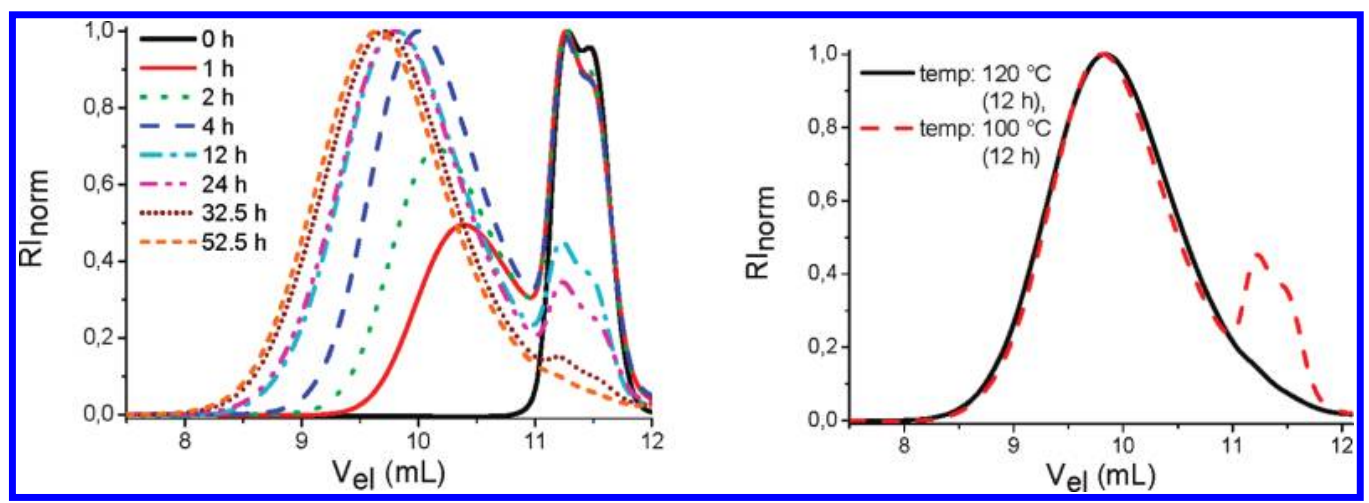

Figure 2. SEC traces for the microwave-assisted copolymerization of EtOx and $\mathrm{Ac}_{4} \mathrm{GlcYnOx}$ after different polymerization times at $100{ }^{\circ} \mathrm{C}($ left $)$ and after $12 \mathrm{~h}$ at 100 and $120^{\circ} \mathrm{C}$, respectively (right).

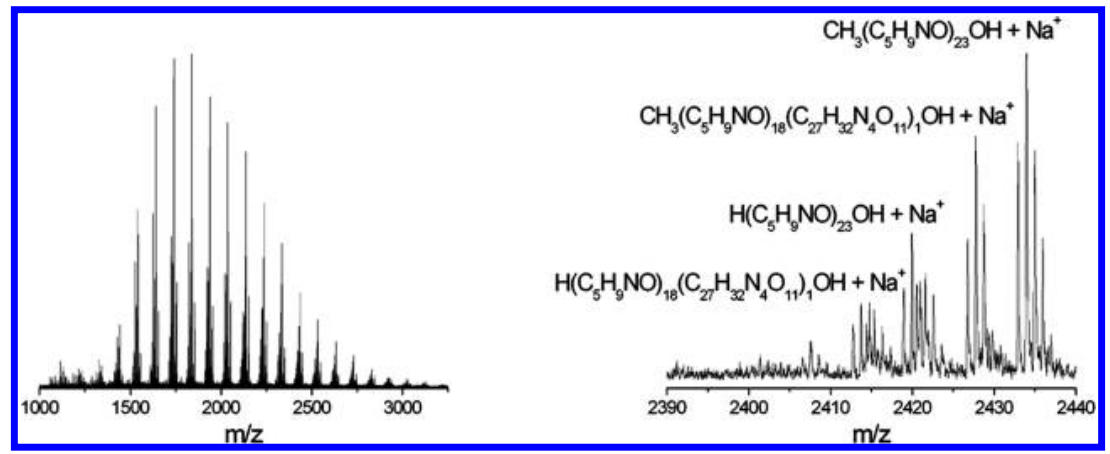

Figure 3. MALDI-TOF MS spectrum (matrix: DCTB, ionization salt: $\mathrm{NaI}$, solvent: $\mathrm{CHCl}_{3}$ ) of the $\mathrm{p}\left(\mathrm{EtOx}\right.$-stat-Ac $\mathrm{GlCYnOx}_{4}$ copolymer (left) with a detailed analysis of a selected part of the spectrum (right).

from ethanol several times yielding a white powder in good yields, large scale, and high purity. The ${ }^{1} \mathrm{H}$ NMR spectrum (Figure 1) clearly shows the sugar signals (between 4 and 5 $\mathrm{ppm})$, the protons of the acetate groups ( $2 \mathrm{ppm})$, as well as the protons of the 2-oxazoline ring (4.05 ppm, $4.45 \mathrm{ppm})$ and the aromatic protons (8 ppm).

Copolymerizations of $\mathrm{Ac}_{4} \mathrm{GlcYnOx}$. 2-Oxazolines exhibit the ability to undergo a ring-opening polymerization when reacted with an electrophilic initiator. As it was shown, this polymerization can possess a living character, as indicated by the absence of chain transfer and termination reactions, under appropriate conditions which have to be optimized for each polymerization system. Parameters, such as the solvent, initiator, and temperature, can have a great influence on the obtained product and have to be studied in detail. In particular, the molecular structure of the monomers has to be considered for the choice of the conditions. Therefore, the copolymerization of $\mathrm{Ac}_{4} \mathrm{GlcYnOx}$ and EtOx was performed at $100^{\circ} \mathrm{C}$ under microwave irradiation to prevent any degradation of the sugar moiety. Because a decrease in the temperature (compared with the optimized EtOx polymerization conditions at $\left.140{ }^{\circ} \mathrm{C}\right)^{37,38}$ is accompanied by a decrease in the polymerization rate, a polymerization time of several hours was required. The rate constant of $\mathrm{EtOx}$ at $100{ }^{\circ} \mathrm{C}$ was determined to be $6.5 \times 10^{-3} \mathrm{~L} \cdot \mathrm{mol}^{-1} \cdot \mathrm{s}^{-1}$, which is one order of magnitude slower than a polymerization at $140{ }^{\circ} \mathrm{C}$ in the microwave. The disappearance of the monomer signal in the SEC, as depicted in Figure 2 (left), allowed a rough estimation of the required time for a full conversion of $\mathrm{Ac}_{4} \mathrm{GlcYnOx}$. The exact calculation of the polymerization rate was not possible with the common methods

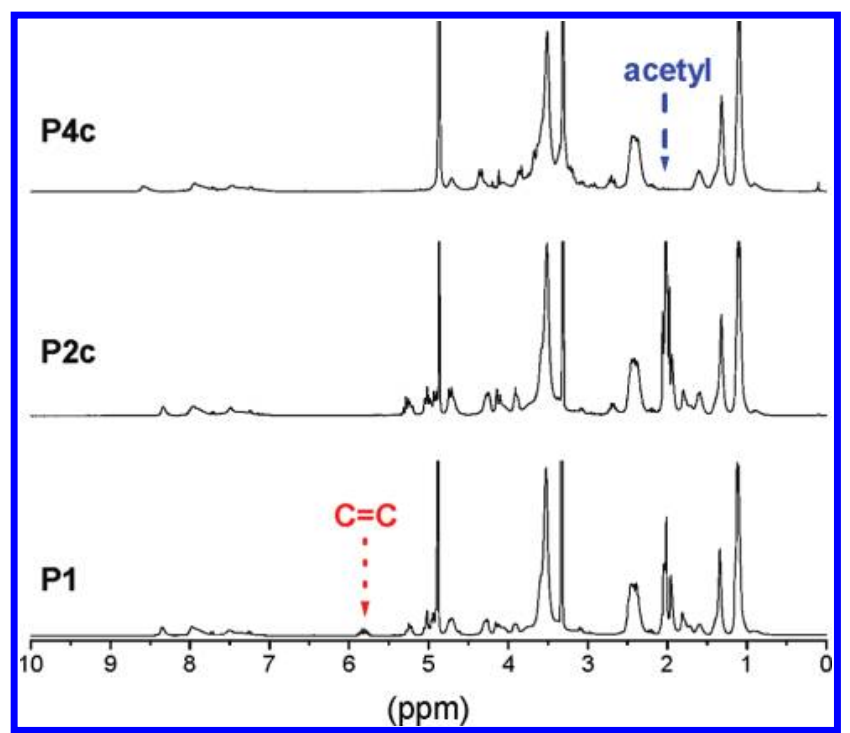

Figure 4. Details of the ${ }^{1} \mathrm{H}$ NMR spectra $\left(300 \mathrm{MHz}, \mathrm{CD}_{3} \mathrm{OD}\right)$ of the copolymers P1, P2c (thiol-ene product) and P4c (after deacetylation).

because $\mathrm{Ac}_{4} \mathrm{GlcYnOx}$ could not be detected in GC. Also, the sugar signals were overlapping with the oxazoline ring signals in the ${ }^{1} \mathrm{H}$ NMR spectrum. However, further experiments elucidated $120{ }^{\circ} \mathrm{C}$ to be the optimal temperature for this copolymerization because of an enhancement of the polymerization, as shown in Figure 2 (right). 
Scheme 3. Schematic Representation of the Thiol-ene Reactions and the Deprotection Reactions Starting from Copolymer P1

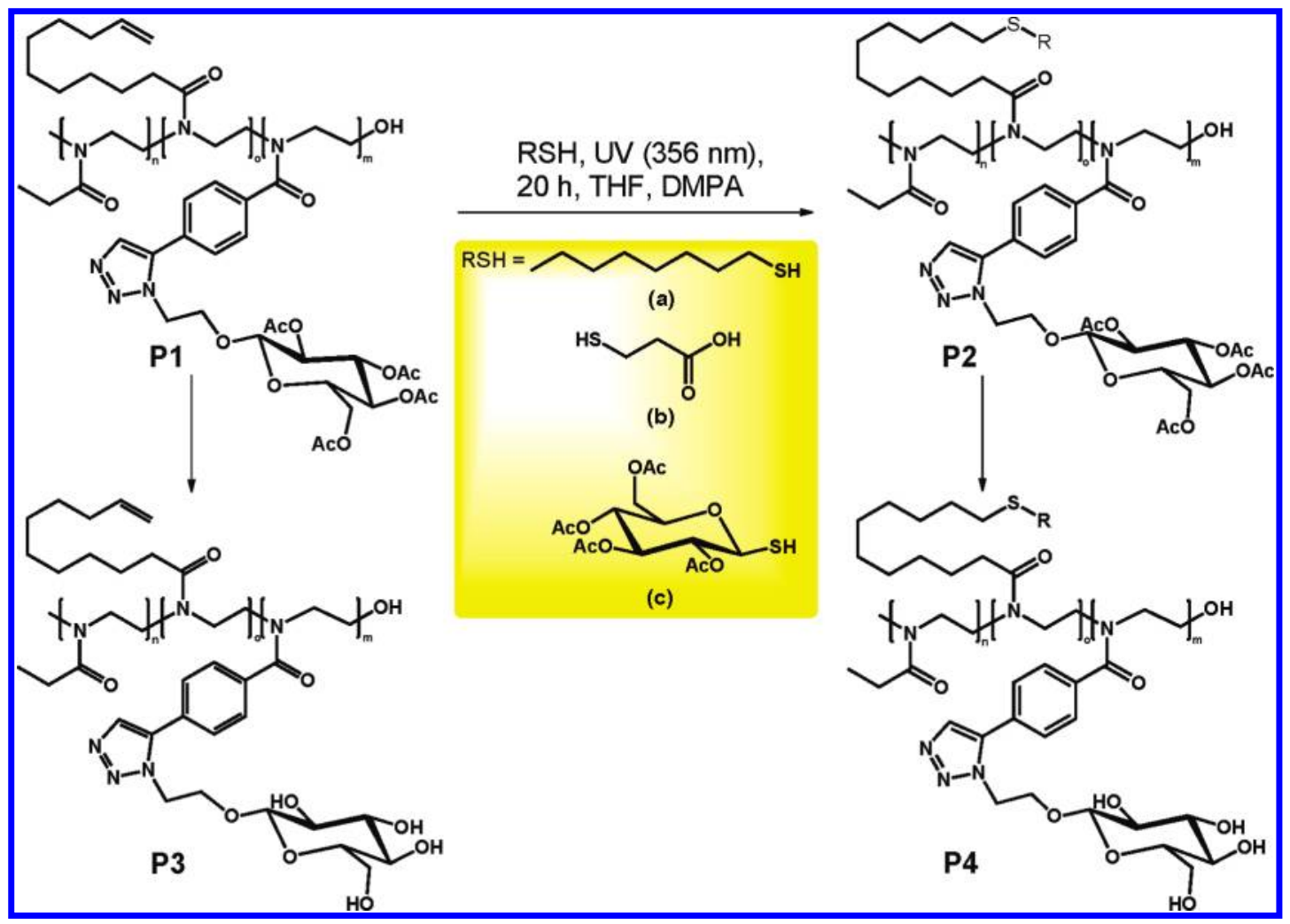

Table 1. Summary of the SEC Analysis Data of the Starting Copolymer P1, the Copolymers after Thiol-ene Photoaddition P2a-c and the Glycopolymers P3, P4a-c (DMA/2.1 $\mathrm{g} \mathrm{L}^{-1}$ LiCl; PS Standard)

$\begin{array}{llllllll}\text { P1 } & \text { P2a } & \text { P2b } & \text { P2c } & \text { P3 } & \text { P4a } & \text { P4b } & \text { P4c }\end{array}$

$M_{\mathrm{n}}\left[\mathrm{g} \mathrm{mol}^{-1}\right] 1360014900145001470017800195001910021700$

$\begin{array}{lllllllll}\text { PDI } & 1.38 & 1.34 & 1.34 & 1.38 & 1.30 & 1.33 & 1.31 & 1.35\end{array}$

Furthermore, the incorporation of $\mathrm{Ac}_{4} \mathrm{GlcYnOx}$ in the copolymer $\mathrm{P}\left(\right.$ EtOx-stat-Ac $\left.\mathrm{All}_{4} \mathrm{YnOx}\right)$ could be confirmed by MALDI-TOF MS, as can be seen in Figure 3. The magnified area of the spectrum revealed the existence of a copolymer formed besides homopolymer of EtOx, which is expected to be ionized much more easily under MALDI-TOF MS conditions. This knowledge encouraged the synthesis of a more advanced copolymer containing an additional monomer, namely, 2-(dec-9-enyl)-2oxazoline, which allows the straightforward postmodification of the resulting copolymer, thus offering the possibility for a finetuning of the copolymer properties with respect to its solution behavior as well as lectin binding properties. All three monomers were mixed under an argon atmosphere with methyl tosylate as initiator and acetonitrile as solvent. After $12 \mathrm{~h}$ of microwave irradiation at $120{ }^{\circ} \mathrm{C}$, the copolymer was washed with water and precipitated in ice-cold diethyl ether. SEC and ${ }^{1} \mathrm{H}$ NMR investigations revealed a reasonable PDI value and the incorporation of all the three monomers, respectively (Figure 4, bottom) [EtOx 25, $\left.\mathrm{DecEnOx} 3, \mathrm{Ac}_{4} \mathrm{GlcYnOx} 4\right]$. The slight increase in the PDI values can be most likely explained by the occurrence of side reactions caused by the triazole ring of the "clicked" sugar monomer.
Thiol-ene Photoaddition and Deacetylation Reactions. With its pendant alkene group in the side chain, the properties of the resulting copolymer could be fine-tuned by applying thiol-ene photoaddition reactions. In this respect, it was possible to control the hydrophilic/hydrophobic ratio of the copolymer by increasing the amount of sugar moieties or by attaching long aliphatic chains as well as to generate a $\mathrm{pH}$-sensitive system using 3-mercaptopropionic acid as thiol component (Scheme 3). The reaction was performed according to the method reported by Hawker et al. ${ }^{39}$ The thiols were added in slight excess ( 2 equiv of $\mathrm{Ac}_{4} \mathrm{GlcSH}$ with respect to the amount of double bonds) up to a large excess (10 equiv of 3-mercaptopropionic acid as well as dodecanethiol with respect to the number of double bonds) to the polymer solution. A radical photoinitiator (DMPA) was employed to accelerate the reaction. All reactions were performed under irradiation overnight at $356 \mathrm{~nm}$ to ensure a complete conversion of the alkene groups as investigated by ${ }^{1} \mathrm{H}$ NMR spectroscopy (Figure 4). To activate the biological potential of the sugar moieties and to increase the hydrophilicity, we treated all copolymers obtained with sodium methanolate in methanol to yield the respective deacetylated materials (P3, P4a-c). A summary of the molar masses and PDI values of the copolymers obtained is given in Table 1. Because of a good solubilization of the free hydroxyl groups of the sugar moieties in DMAc associated with a larger hydrodynamic volume, an increase in the molar mass in SEC was observed even if the theoretical molar mass was decreasing after the deprotection (Figure 5). In addition, the deprotection could be monitored by the disappearance of the acetate signals in the ${ }^{1} \mathrm{H}$ NMR spectra. 


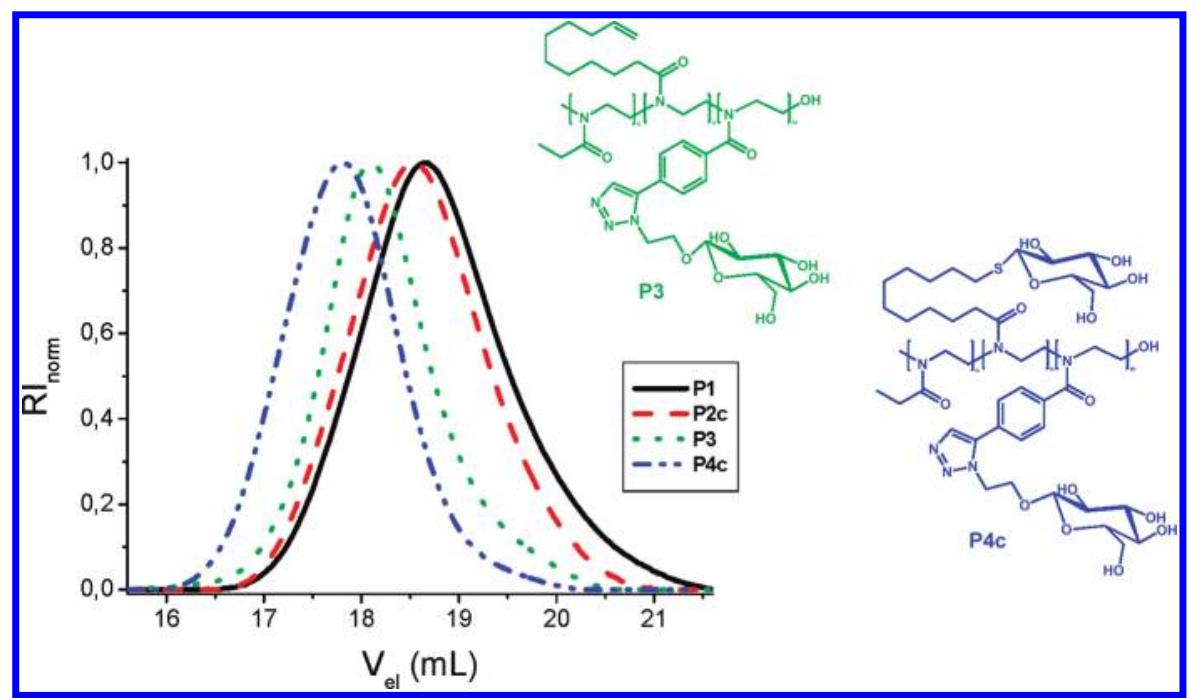

Figure 5. SEC traces of the initially obtained copolymer (P1) and the product of the thiol-ene reaction with GlcAc 4 SH (P2c) and their deprotected products (P3, P4c) (DMA/2.1 $\mathrm{g} \mathrm{L}^{-1} \mathrm{LiCl}$; PS standard).

Table 2. Summary of the Cloud-Point Temperatures of the Glycopolymers ( $4 \mathrm{mg} \mathrm{mL}$ ) Obtained by Turbidity Measurements $($ n.d. $=$ not determined $)$

\begin{tabular}{lllll} 
& \multicolumn{1}{c}{$\mathbf{P 3}$} & \multicolumn{1}{c}{ P4a } & P4b & \multicolumn{1}{c}{ P4c } \\
PBS & $21{ }^{\circ} \mathrm{C}$ & not soluble & soluble & $33{ }^{\circ} \mathrm{C}$ \\
pH 4 buffer & n.d. & n.d. & $30.5{ }^{\circ} \mathrm{C}$ & n.d. \\
pH 10 buffer & n.d. & n.d. & soluble & n.d. \\
$\mathrm{H}_{2} \mathrm{O}$ & soluble & soluble & $25.5^{\circ} \mathrm{C}$ & $50{ }^{\circ} \mathrm{C}$ \\
$0.015 \mathrm{mM} \mathrm{NaCl}_{\mathrm{aq}}$ & $21.6^{\circ} \mathrm{C}$ & not soluble & $12.2^{\circ} \mathrm{C}$ & $27.6{ }^{\circ} \mathrm{C}$ \\
$0.005 \mathrm{mM} \mathrm{NaCl}_{\mathrm{aq}}$ & $21.1^{\circ} \mathrm{C}$ & not soluble & $12.2^{\circ} \mathrm{C}$ & $27.9^{\circ} \mathrm{C}$ \\
\hline
\end{tabular}

Solubility of the Copolymers in Aqueous Media. The temperature-dependent solubility properties of the PEtOx-based glycopolymers $\mathbf{P} 3$ and $\mathbf{P} \mathbf{4} \mathbf{a}-\mathbf{c}$ were investigated by turbidimetry measurements at a polymer concentration of $4 \mathrm{mg} \cdot \mathrm{mL}^{-1}$ in the temperature range from 2 to $100{ }^{\circ} \mathrm{C}$. The results of the performed solubility screening in water and aqueous $\mathrm{NaCl}$ solutions as well as in buffered solutions are provided in Table 2, and exemplary turbidity curves are shown in Figure 6.

The coil to globule transition of the thermoresponsive polymers in aqueous solution occurred abruptly during heating and was followed by the formation of larger particles. Even though those larger particles slowly redissolve during the cooling run, the phase transitions were found to be fully reversible, as demonstrated by a similar behavior during the second heating/cooling cycle. In addition, glycopolymer P4c was used for a more detailed analysis concerning the dependence of the polymer concentration on the cloud-point temperature $\left(T_{\mathrm{cp}}\right)$. As shown in Figure 6, $T_{\mathrm{cp}}$ is increasing from 32 to $58^{\circ} \mathrm{C}$ with decreasing concentration, which is important to keep in mind with respect to further investigations of the thermoresponsive behavior of the polymer.

Prior to the discussion of the solubility behavior of each of the investigated polymers, it should be noted that PEtOx is known to exhibit LCST behavior in aqueous solution above a DP of 100 and in a temperature range above $70{ }^{\circ} \mathrm{C} .{ }^{40,41}$ However, copolymerization with monomers that carry longer alkyl chain substituents in the two-position of the oxazoline ring renders the copolymers more hydrophobic and thus decreases the $T_{\mathrm{cp}}$ of the resulting copolymers. ${ }^{42,43}$ The glucose moiety should increase the hydrophilicity of the polymers, as has been observed by Schlaad for copolymers that are based on poly(2-iso-propyl-2oxazoline $).{ }^{44}$ In addition, the long and flexible decenyl chain from DecEnOx and the gradient copolymer structure may enable micellization, which induces an additional underlying mechanism of conformational change to the pure observation of a coil to globule transition of a LCST polymer.

Apparently, the solubility behavior of $\mathbf{P} 3$ is strongly influenced by the presence of salts. The polymer solution showed $T_{\mathrm{cp}}$ values around $21^{\circ} \mathrm{C}$ in $\mathrm{PBS}$ and in aqueous $\mathrm{NaCl}$ solutions, whereas the binary system P3/water did not reveal any cloud point. Even though it is well known that $\mathrm{NaCl}$ has a salting out effect on many thermoresponsive polymers, ${ }^{45}$ the large difference in solubility cannot simply be attributed to this fact. Indeed, DLS measurements of P3 in water revealed the presence of larger ill-defined aggregates at $25^{\circ} \mathrm{C}$, whereas in PBS particles of sizes below $10 \mathrm{~nm}$ could be observed that most likely correspond to individually dissolved polymer coils or small micelles (Figure S1 of the Supporting Information). It appears that in water aggregated structures are formed that contain the hydrophobic decenyl chains in the core and the hydrophilic glucose moieties in the shell. These structures seem to be disrupted by $\mathrm{NaCl}$ as chaotropic salt from the Hofmeister series that strengthens hydrophobic interactions. The increased hydrophilicity of P4c due to the presence of further glucose moieties results in elevated $T_{\mathrm{cp}}$ values of the polymer in PBS and $\mathrm{NaCl}$ solutions when compared with P3. In addition, the attachment of the hydrophilic glucose functionalities at the hydrophobic decenyl side chain prevents the formation of aggregated structures so that $\mathbf{P} 4 \mathbf{c}$ also displays a cloud point in pure water. Attachment of an aliphatic dodecyl chain to the decenyl chain renders P4a more hydrophobic so that it becomes insoluble in $\mathrm{PBS}$ and $\mathrm{NaCl}$ solutions. It favors the formation of small micellar structures in water so that the polymer does not exhibit a coil-to-globule transition anymore (Figure S2 of the Supporting Information).

The more complex solubility behavior of the acid containing copolymer $\mathbf{P} \mathbf{4 b}$ in aqueous solutions with and without additives might be explained as follows: In buffered solutions at $\mathrm{pH} 10$ as well as in PBS ( $\mathrm{pH} 7.4$ ), the carboxylic acid moieties are fully 


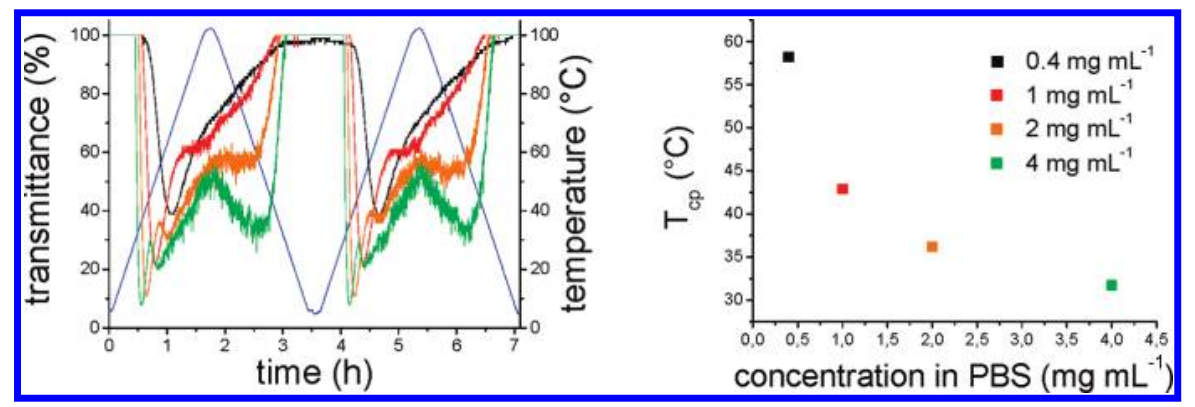

Figure 6. Turbidity curves for the determination of the cloud points of P4c in PBS buffer (left) and graphical illustration of the dependence of the cloud point temperature $\left(T_{\mathrm{cp}}\right)$ on the concentration (right).

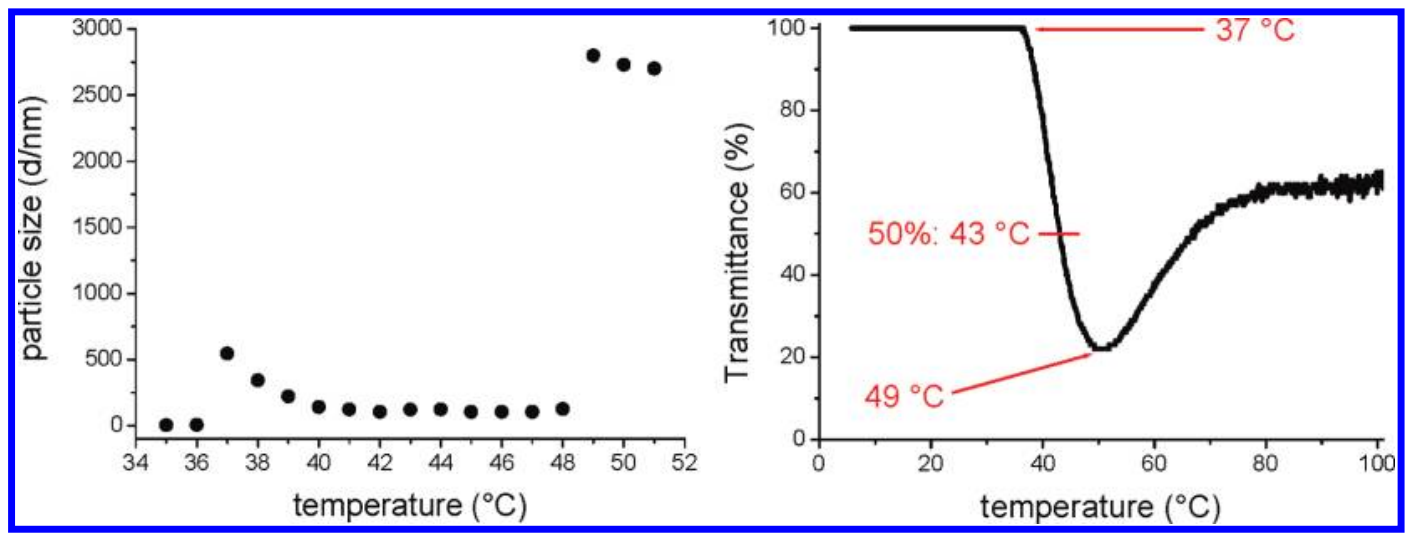

Figure 7. Temperature dependence of the particle size determined by DLS measurements (left) and transmittance (right) of P4c $\left(1 \mathrm{mg} \cdot \mathrm{mL}^{-1}\right.$; PBS solution).

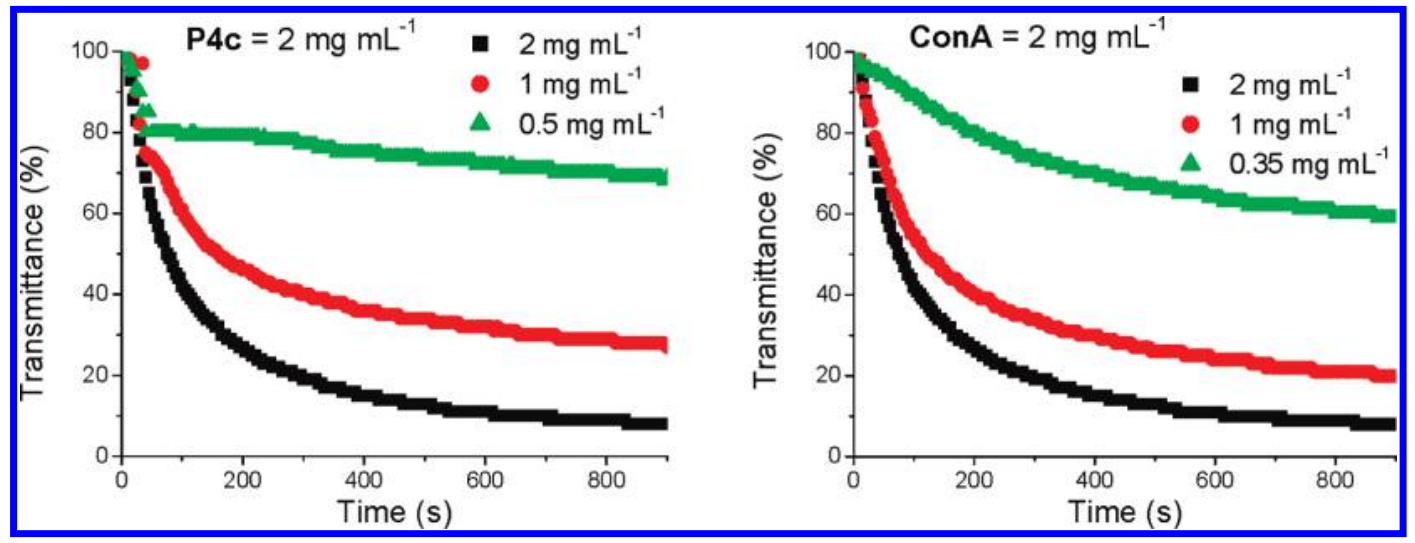

Figure 8. Concanavalin A lectin interaction with glycopolymer P4c: turbidity as a function of time for constant P4c concentration (left) and turbidity as a function of time for constant ConA concentration at $25^{\circ} \mathrm{C}$.

deprotonated, which results in a higher hydrophilicity of the, thus, charged copolymer. Already in deionized water the rather weak carboxylic acid will be partially protonated, leading towards the formation of intramolecular $\mathrm{H}$ bonds between the protonated carboxylic acid as $\mathrm{H}$ bond donor and oxygen atoms of carbonyl moieties of the POx backbone as $\mathrm{H}$ bond acceptors. ${ }^{46}$ As a result, these positions are not available for $\mathrm{H}$ bonding with the surrounding water molecules (which keep the macromolecule in solution) anymore; therefore, the solution displays a $T_{\mathrm{cp}}$ of $30.5{ }^{\circ} \mathrm{C}$ in buffered solution at $\mathrm{pH} 4$ and at $25.5^{\circ} \mathrm{C}$ in water, respectively. Because we could also observe a very strong influence of salt additives upon the solubility behavior of P3 and $\mathbf{P} \mathbf{4} \mathbf{b}$, the rather large difference between those $T_{\mathrm{cp}}$ values may be a result of the salts inside the buffer that was used.

In addition, the coil-to-globule transition of $\mathbf{P 4 c}$ in PBS was studied by DLS experiments at a concentration of $1 \mathrm{mg} \cdot \mathrm{mL}^{-1}$ (Figure 7). Below $37^{\circ} \mathrm{C}$, particle sizes below $10 \mathrm{~nm}$ were observed, indicating the presence of single polymer coils. At $37{ }^{\circ} \mathrm{C}$, which corresponds to the onset of the decrease in transmittance during the turbidity measurement, the collapsed chains aggregated into globules of sizes around $300 \mathrm{~nm}$. Further increase in temperature up to $48{ }^{\circ} \mathrm{C}$ resulted in a shrinkage of those globules before they further aggregate into larger agglomerates at $49{ }^{\circ} \mathrm{C}$. This agglomeration was manifested by an 
increase in transmittance during the turbidity measurement because of the passing of light through the mixture around those larger agglomerates. It might be speculated that more hydrophobic parts of the copolymer collapse first and are still somewhat stabilized by more hydrophilic parts that precipitate at higher temperatures.

Lectin Interaction Studies. As discussed above, glycopolymers with pendant sugar moieties exhibit an enormous advantage compared with single sugar units because they are capable of multivalently binding lectins (carbohydrate-binding proteins) in the process known as the "cluster-glycoside effect". As one member of these proteins, Concanavalin A (ConA) is known to specifically bind to mannosyl and glucosyl residues. ${ }^{6}$ ConA exhibits four binding sites enabling the binding of up to four sugar residues resulting in the formation of aggregates/clusters of the protein. This agglomeration can be monitored by a turbidity assay. The addition of a glycopolymeric solution to a clearly dissolved ConA renders the mixture turbid due to the described formation of clusters. Therefore, it allows the measurement of the transmittance decrease in the solution during the interaction. In this context, the glycopolymer P4c with increased glucose content was investigated in view of its ability to bind to ConA. To check the rate of binding, we prepared a solution of P4c in PBS $\left(4 \mathrm{mg} \cdot \mathrm{mL}^{-1}\right)$ and stirred it for $10 \mathrm{~min}$. To prevent a turbidity of the glycopolymer solution due to its coil-to-globule transition, we set the temperature to $25{ }^{\circ} \mathrm{C}$. The addition of different concentrations of ConA in PBS resulted in an immediate precipitation, consistent with a decrease in the transmittance of the solution. The higher the concentration of the ConA solution, the faster the complexation occurred, as demonstrated by the steeper slope of the transmittance versus time curve in Figure 8 (left). A similar behavior was obtained when the ConA concentration was kept constant, whereas the P4c concentration was varied. Fast precipitation was observed for the highest polymer concentration reaching almost $0 \%$ transmittance. To gain an idea about the effect of the LCST behavior of the glycopolymer on the conjugation ability with ConA, we performed measurements at $37^{\circ} \mathrm{C}$ with a $1 \mathrm{mg} \cdot \mathrm{mL}^{-1} \mathbf{P} 4 \mathrm{c}$ solution. Because of the incipient coil-to-globule transition at this temperature, a slight decrease in the transmittance to $95 \%$ was observed. Upon the addition of ConA (final concentration: $2 \mathrm{mg} \cdot \mathrm{mL}^{-1}$ ), the transmittance decreased with a 2 min delay. This effect might be caused by the direct addition of the ConA and the time required to completely dissolve the ConA. Furthermore, it might be ascribed to the fact that some polymer chains are collapsed at this temperature and thus hinder the conjugation with the glucose moieties.

\section{CONCLUSIONS}

The synthesis of a new glucose-substituted 2-oxazoline monomer via $\mathrm{CuAAC}$ is described. The copolymerization with 2-ethyl-2oxazoline and 2-(dec-9-enyl)-2-oxazoline yielded well-defined copolymers. The latter copolymers were extensively studied in view of their aqueous solution behavior. Exploiting thiol-ene chemistry, the pendant alkene groups of the 2-(dec-9-enyl)-2oxazoline were modified with several thiols, such as dodecanethiol, 3-mercaptopropionic acid, and 2,3,4,6-tetra-O-acetyl-1thio- $\beta$-D-gluco-pyranose. The deacetylation of the sugar moieties yielded glycopolymers with different solution behaviors showing thermosensitivity as well as $\mathrm{pH}$ sensitivity in water and $\mathrm{PBS}$, respectively. In addition, the glucose content was increased when using 2,3,4,6-tetra- $O$-acetyl-1-thio- $\beta$-Dglucopyranose. This copolymer exhibits thermoresponsive properties in the physiological temperature range depending on the concentration of the copolymer in PBS solution. Lectin binding studies with this copolymer revealed a fast conjugation, as demonstrated by a turbidity assay. With this sugar-substituted 2 -oxazoline monomer in hand a variety of new glyco-poly(2oxazoline)s with tunable solution behavior can be prepared, which possess the ability to bind to specific lectins by the straightforward exchange of the sugar moiety during the monomer synthesis.

\section{ASSOCIATED CONTENT}

S Supporting Information. DLS data. This material is available free of charge via the Internet at http://pubs.acs.org.

\section{AUTHOR INFORMATION}

\section{Corresponding Author}

*Fax: +49 3641948 202. E-mail: ulrich.schubert@uni-jena.de.

\section{ACKNOWLEDGMENT}

We thank the Dutch Polymer Institute (DPI, Technology area HTE) for financial support. K.K. is grateful to the Landesgraduiertenfoerderung Thueringen for financial support. R.H. (Veni-grant) and USS (Vici-grant) thank The Netherlands Scientific Organisation (NWO) for financial support. We thank the Thuringian Ministry for Education, Science and Culture (grant \#B514-09051, NanoConSens).

\section{REFERENCES}

(1) Collins, B. E.; Paulson, J. C. Curr. Opin. Chem. Biol. 2004, 8, $617-625$.

(2) Stillman, B. N.; Hsu, D. K.; Pang, M.; Brewer, C. F.; Johnson, P.; Liu, F. T.; Baum, L. G. I. Immunol. 2006, 176, 778-789.

(3) Gabius, H. J.; Siebert, H. C.; Andre, S.; Jimenez-Barbero, J.; Ruediger, H. ChemBioChem 2004, 5, 741-764.

(4) Dimick, S. M.; Powell, S. C.; McMahon, S. A.; Moothoo, D. N.; Naismith, J. H.; Toone, E. J. I. Am. Chem. Soc. 1999, 121, 10286-10296.

(5) Lundquist, J. J.; Toone, E. I. Chem. Rev. 2002, 102, 555-578.

(6) Ambrosi, M.; Cameron, N. R.; Davis, B. G. Org. Biomol. Chem. 2005, 3, 1593-1608.

(7) Narain, R.; Armes, S. P. Biomacromolecules 2003, 4, 1746-1758.

(8) Vazquez-Dorbatt, V.; Maynard, H. D. Biomacromolecules 2006, 7, 2297-2302.

(9) Ting, S. R. S.; Chen, G. J.; Stenzel, M. H. Polym. Chem. 2010, 1, 1392-1412.

(10) Slavin, S.; Burns, J.; Haddleton, D. M.; Becer, C. R. Eur. Polym. J. 2011, 47, 435-446.

(11) Aoi, K.; Tsutsumiuchi, K.; Aoki, E.; Okada, M. Macromolecules 1996, 29, 4456-4458.

(12) Aoi, K.; Tsutsumiuchi, K.; Okada, M. Macromolecules 1994, 27, 875-877.

(13) Tsutsumiuchi, K.; Aoi, K.; Okada, M. Macromolecules 1997, 30, 4013-4017.

(14) Seeliger, W.; Aufderhaar, E.; Diepers, W.; Feinauer, R; Nehring, R; Thier, W.; Hellmann, H. Angew. Chem.. Int. Ed. Engl. 1966, 5, 857-888.

(15) Kagiya, T.; Narisawa, S.; Maeda, T.; Fukui, K. J. Polym. Sci., Part C: Polvm. Lett. 1966, 4, 441-445.

(16) Bassiri, T. G.; Levy, A.; Litt, M. J. Polym. Sci., Part C: Polym. Lett. 1967, 5, 871-879.

(17) Tomalia, D. A.; Sheetz, D. P. J. Polym. Sci., Part A: Polym. Chem. 1966, 4, 2253-2265. 
(18) Knop, K.; Hoogenboom, R.; Fischer, D.; Schubert, U. S. Angew. Chem. Int. Ed. 2010, 49, 6288-6308.

(19) Adams, N.; Schubert, U. S. Adv. Drug Delivery Rev. 2007, $59,1504-1520$.

(20) Hoogenboom, R. Angew. Chem. Int. Ed. 2009, 48, 7978-7994.

(21) Lin, P. Y.; Clash, C.; Pearce, E. M.; Kwei, T. K.; Aponte, M. A. J. Polym. Sci.,Part B: Polvm. Phvs. 1988, 26, 603-619.

(22) Kempe, K.; Lobert, M.; Hoogenboom, R.; Schubert, U. S. J. Polym. Sci., Part A: Polvm. Chem. 2009, 47, 3829-3838.

(23) Kobayashi, S.; Uyama, H.; Higuchi, N.; Saegusa, T. Macromolecules 1990, 23, 54-59.

(24) Kobayashi, S.; Iijima, S.; Igarashi, T.; Saegusa, T. Macromolecules 1987, 20, 1729-1734.

(25) Aoi, K.; Okada, M. Prog. Polvm. Sci. 1996, 21, 151-208.

(26) Saegusa, T.; Fujii, H.; Ikeda, H. Macromolecules 1972, 5, $359-362$.

(27) Saegusa, T.; Ikeda, H. Macromolecules 1973, 6, 808-811.

(28) Kobayashi, S.; Uyama, H. J. Polym. Sci., Part A: Polym. Chem. 2002, 40, 192-209.

(29) Takasu, A.; Kojima, H. J. Polym. Sci., Part A: Polym. Chem. 2010, 48, 5953-5960.

(30) Cortez, M. A.; Grayson, S. M. Macromolecules 2010, 43, 4081-4090.

(31) Cesana, S.; Auernheimer, J.; Jordan, R.; Kessler, H.; Nuyken, O. Macromol. Chem. Phys. 2006, 207, 183-192.

(32) Taubmann, C.; Luxenhofer, R.; Cesana, S.; Jordan, R. Macromol. Biosci. 2005, 5, 603-612.

(33) Aoi, K.; Suzuki, H.; Okada, M. Macromolecules 1992, 25, 7073-7075.

(34) Mikata, Y.; Shinohara, Y.; Yoneda, K.; Nakamura, Y.; Esaki, K.; Tanahashi, M.; Brudziñska, I.; Hirohara, S.; Yokoyama, M.; Mogami, K.; Tanase, T.; Kitayama, T.; Takashiba, K.; Nabeshima, K.; Takagi, R.; Takatani, M.; Okamoto, T.; Kinoshita, I.; Doe, M.; Hamazawa, A.; Morita, M.; Nishida, F.; Sakakibara, T.; Orvig, C.; Yano, S. J. Org. Chem. 2001, 66, 3783-3789.

(35) Kempe, K.; Vollrath, A.; Schaefer, H. W.; Poehlmann, T. G.; Biskup, C.; Hoogenboom, R.; Hornig, S.; Schubert, U. S. Macromol. Rapid Commun. 2010, 31, 1869-1873.

(36) Witte, H.; Seeliger, W. Liebigs Ann. Chem. 1974, 996-1009.

(37) Wiesbrock, F.; Hoogenboom, R.; Leenen, M. A. M.; Meier, M. A. R.; Schubert, U. S. Macromolecules 2005, 38, 5025-5034.

(38) Wiesbrock, F.; Hoogenboom, R.; Abeln, C. H.; Schubert, U. S. Macromol. Rapid Commun. 2004, 25, 1895-1899.

(39) Campos, L. M.; Killops, K. L.; Sakai, R.; Paulusse, J. M. J.; Damiron, D.; Drockenmuller, E.; Messmore, B. W.; Hawker, C. J. Macromolecules 2008, 41, 7063-7070.

(40) Christova, D.; Velichkova, R.; Loos, W.; Goethals, E. J.; Du Prez, F. Polvmer 2003, 44, 2255-2261.

(41) Hoogenboom, R; Thijs, H. M. L.; Jochems, M. J. H. C.; van Lankvelt, B. M.; Fijten, M. W. M.; Schubert, U. S. Chem. Commun. 2008, $5758-5760$.

(42) Lambermont-Thijs, H. M. L.; Hoogenboom, R.; Fustin, C. A.; Bomal-D'Haese, C.; Gohy, J. F.; Schubert, U. S. J. Polym. Sci., Part A: Polvm. Chem. 2009, 47, 515-522.

(43) Huber, S.; Jordan, R. Colloid Polvm. Sci. 2008, 286, 395-402.

(44) Diehl, C.; Schlaad, H. Macromol. Biosci. 2009, 9, 157-161.

(45) Bloksma, M. M.; Bakker, D. J.; Weber, C.; Hoogenboom, R.; Schubert, U. S. Macromol. Rapid Commun. 2010, 31, 724-728.

(46) Weber, C.; Becer, C. R.; Guenther, W.; Hoogenboom, R.; Schubert, U. S. Macromolecules 2010, 43, 160-167. 